\title{
Protective effect of paeoniflorin against glutamate-induced neurotoxicity in PC12 cells via Bcl-2/Bax signal pathway
}

\author{
Rong Sun ${ }^{1}, \mathrm{Ke}$ Wang ${ }^{2}$, Dongdong $\mathrm{Wu}^{3}$, Xiaoyu Li ${ }^{4}$, Yangbing $\mathrm{Ou}^{4}$ \\ 1Shandong Academy of Chinese Medicine, 2Jiangsu Institute of Nuclear Medicine, ${ }^{3}$ Chinese Academy of Sciences, ${ }^{4}$ Shandong \\ University of Traditional Chinese Medicine, China
}

\begin{abstract}
Paeoniflorin (PF), a monoterpene glycoside isolated from the aqueous extract of Radix Paeoniae Alba, is widely used in Traditional Chinese Medicine (TCM) for the treatment of neurodegenerative disorders such as Alzheimer's disease $(A D)$ and Parkinson's disease (PD). In this study, we investigated the protective mechanism of PF on glutamate-induced neurotoxicity in cultured rat pheochromocytoma (PC12) cells. PC12 cells were cultured in vitro, cell viability was assessed by MTT assay, cell apoptosis as well as mitochondrial membrane potential (MMP) were detected by flow cytometric analysis and the expression profiles of apoptosis-related proteins including $\mathrm{BCl}-2$ and $\mathrm{Bax}$ were investigated by western blot. The results showed that PF could protect PC12 cells against glutamate-induced injury in a concentration-dependent manner and the mechanism of neuroprotective effect of PF was closely associated with up-regulation of Bcl-2 and down-regulation of Bax. It demonstrated that PF has neuroprotective effect on glutamate-induced apoptosis in $P C 12$ cells via regulating mitochondrial membrane potential and $\mathrm{BCl}-2 / \mathrm{Bax}$ signal pathway.
\end{abstract}

Key words: paeoniflorin, glutamate, PC12 cells, neuroprotective effect, signal pathway.

\section{Introduction}

Traditional Chinese herbal medicine, with fewer side effects and better safety, has been widely investigated for drug development. Radix Paeoniae alba, the dry root of Paeonia, has been used for treating cerebral ischemia, epilepsy, and neurodegenerative disorders such as Alzheimer's disease [22] and Parkinson's disease [9]. Paeoniflorin (PF), a monoterpene glycoside isolated from the aqueous extract of Radix Paeoniae alba, has been identified as the main active ingredient responsible for the biological activities. Its beneficial effects can be found in improvement of learning and memory, analgesia, conscious-sedation and antioxi- dation $[10,19]$. Previous studies have demonstrated that PF might exert its neuroprotective effect by activating adenosine A1 receptor, ameliorating the function of the cholinergic nerve, regulating ion channel homeostasis, retarding oxidative stress and apoptosis of neurons and promoting nerve growth.

Glutamate, one of the 20-22 proteinogenic amino acids, is an important neurotransmitter that plays a key role in long-term potentiation and important for learning and memory in the central nervous system $[4,16]$. Under normal conditions, glutamate is released into the synaptic cleft and binds to glutamate receptors resulting in the propagation of an action poten- 
tial $[8,18]$. However, increased amounts of glutamate in the synaptic cleft can lead to neurotoxicity that has been well-established. It has been reported that plasma levels of glutamate in Alzheimer's disease patients were significantly higher than those in healthy controls and glutamate dysfunction drive to basal ganglia output nuclei is considered a likely contributor to the pathogenesis of Parkinson's disease [2].

Imbalance within the nerve cellslevels of glutamate in $A D$ patients were significantly higher than those healthy controls. PC12 cell line is derived from a pheochromocytoma of rat adrenal medulla and can be induced to stop dividing and terminally differentiate when treated with high concentrations of glutamate $[5,8,11]$. This feature makes PC12 cells to be a useful model system for neuronal damage studies. Previous works reported that PF could exert a neuroprotective effect on glutamate-induced neurotoxicity in PC12 cells by inhibiting oxidative stress and $\mathrm{Ca}^{2+}$ overload [8]. In this study, we used different approaches to evaluate the neuroprotective effect of PF and investigated the potential mechanism.

\section{Material and methods \\ Drugs and reagents}

Paeoniflorin was purchased from the National Institute for the Control of Pharmaceutical and Biological Products of China (Beijing, China). PC12 cells were obtained from the Shanghai Institute of Cell Biology, Chinese Academy of Sciences (Shanghai, China). Rhodamine123 (Rh123) was purchased from Sigma-Aldrich (St Louis, Mo, USA). DMEM culture medium and foetal bovine serum were purchased from Gibco (Grand Island, NY, USA). PI, RnaseA, dimethyl sulfoxide (DMSO) and ECL kit were purchased from Beyotime (Nantong, China). The information about the monoclonal antibodies used in this study shows as follows: Bax (PharMingen, CA, USA), Bcl-2 (Santa Cruz, CA, USA), $\beta$-actin (Santa Cruz, CA, USA), HRP conjugated goat anti rabbit secondary antibody and BeyoECL Plus (Beyotime, Nantong, China). All other chemicals and reagents were of analytical grade.

\section{Cell culture and treatments}

PC12 cells were cultured in flasks at $37^{\circ} \mathrm{C}$ under an atmosphere of $5 \% \mathrm{CO}_{2} / 95 \%$ air in DMEM medium supplemented with $10 \%$ heat-inactivated foetal bovine serum and $1 \%$ penicillin-streptomycin. For the experiments, the cells were detached and re-seeded in plates. $24 \mathrm{~h}$ after seeding, the cells were treated with glutamate (30 mM) with the absence or presence of different concentrations of PF (0.1, 1.0 and $10 \mu \mathrm{M})$ for an additional $24 \mathrm{~h}$.

\section{Cell viability assay}

Cell viability was measured by MTT assay as described in a reference [6]. PC12 cells $\left(2 \times 10^{4}\right.$ per well) were seeded in 96-well plates. After overnight incubation, PC12 cells were treated with glutamate $(30 \mathrm{mM})$ or glutamate $(30 \mathrm{mM})$ plus various concentrations of PF $(0.1,1.0$ and $10 \mu \mathrm{M})$ for $24 \mathrm{~h}$. Following incubation, $10 \mu \mathrm{l}$ MTT $(5 \mathrm{mg} / \mathrm{ml})$ were added to each well. After $4 \mathrm{~h}$ at $37^{\circ} \mathrm{C}$, the culture medium was removed and $100 \mu \mathrm{l}$ DMSO was added to dissolve the formazan crystals. Absorbance was measured at $570 \mathrm{~nm}$ with an ELISA reader (Model680, Bio-Rad, USA). Cell viability was expressed as a percentage of the value against the nontreated control group.

\section{Measurement of cell apoptosis}

DNA gel electrophoresis assay was used to examine the effect of cell apoptosis. PC12 cells treated with or without drugs for $24 \mathrm{~h}$ were harvested by centrifugation and washed twice with ice-cold PBS. The washed cells were fully re-suspended in lysis buffer $(50 \mathrm{mM}$ Tris- $\mathrm{HCl}, \mathrm{pH}$ 8.0, $10 \mathrm{mM}$ EDTA, and 0.5\% SDS) plus $0.2 \mu \mathrm{l}$ Rnase $\mathrm{A}$. After $1 \mathrm{~h}$ incubation at $50^{\circ} \mathrm{C}$, proteinase $\mathrm{K}$ was added and incubated for another hour. DNA fragments in samples were separated on 1\% agarose gel and visualized under ultraviolet light after staining with ethidium bromide. Flow cytometric analysis was used to determine the apoptosis ratio caused by drugs. PC12 cells $\left(2 \times 10^{5}\right.$ per well) were seeded in 6-well plates and treated with or without drugs as mentioned before. Cells were harvested by centrifugation, fixed gently by adding $70 \%$ ethanol (in PBS) in $4^{\circ} \mathrm{C}$ overnight, before being resuspended in PBS containing $40 \mu \mathrm{g} / \mathrm{mL} \mathrm{PI}$ and $0.1 \mathrm{mg} / \mathrm{mL}$ RNase and 0.1\% Trixon X-100 in a dark room. After 30 minutes at $37^{\circ} \mathrm{C}$, the cells were analyzed by flow cytometry (Becton-Dickinson, CA, USA) with an argon ion laser at $488 \mathrm{nM}$. The data were collected by Cell Quest software (Becton-Dickinson, CA, USA).

\section{Analysis of mitochondrial membrane potential (MMP)}

For the measurement of mitochondrial membrane potential, PC12 cells $\left(1 \times 10^{5}\right.$ per well $)$ treated with 
drugs were incubated with $5 \mu \mathrm{M}$ Rh123 for 30 min. After collection, excess rhodamine was removed by washing and the cells were incubated at $37^{\circ} \mathrm{C}$ for the indicated lengths of time. Then, cellular levels of Rh123 were measured by flow cytometry (Becton-Dickinson, (A, USA).

\section{Relative expression of Bcl-2/Bax signal pathway}

The expression profile of apoptosis-related proteins including $\mathrm{Bcl}-2$ and Bax was examined by western blot using $\beta$-actin as the loading control. The total proteins were collected from PC12 cells treated with or without drugs for $24 \mathrm{~h}$ as described previously and the concentration of which was determined with the Bradford method. Then, samples were fractionated on SDS-PAGE gel and transferred onto PVDF membrane. The membrane was blocked for $1 \mathrm{~h}$, immunoblotted with a specific primary antibody at $4^{\circ} \mathrm{C}$ overnight and then incubated for $1 \mathrm{~h}$ with a HRP-conjugated secondary antibody. Bound antibodies were detected by ECL kit and the density ratio of the protein to $\beta$-actin was calculated using the analysis tools.

\section{Statistical analysis}

Results are expressed as mean \pm SD from at least three independent experiments. Two-group comparisons were performed using Student's t-test. Multiple-

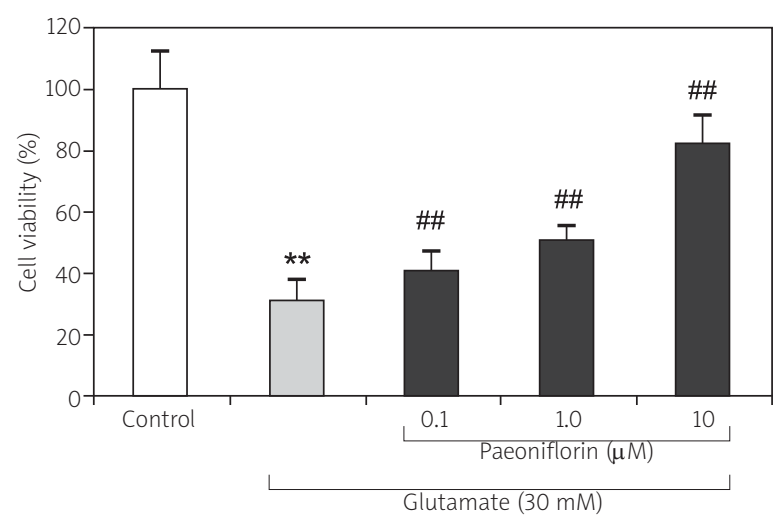

Fig. 1. MTT assays for the effect of PF in PC12 cells. The cell viability was significantly decreased after $24 \mathrm{~h}$ exposure to glutamate $(30 \mathrm{mM})$, however, $\mathrm{PF}$ at a concentration of $0.1,1$ and $10 \mu \mathrm{M}$ blocked this effect significantly. $\left({ }^{* *} p<0.01\right.$ vs. control group, $\# p<0.01$ vs. glutamate group). group comparisons were performed using one-way analysis of variance and Fisher's least significant difference (equal variances assumed) or Dunnett's T3-test (equal variances not assumed). Values of $p<0.05$ were defined as statistically significant.

\section{Results}

\section{Effect of paeoniflorin on glutamate- induced cell viability in PC12 cells}

PC12 cells were incubated with or without drugs for $24 \mathrm{~h}$ and cell viability was determined by MTT assay. Upon treatment with glutamate $(30 \mathrm{mM})$, cell viability was significantly reduced as compared with the control group. When treated with a combination of glutamate at $30 \mathrm{mM}$ plus PF at different concentration (0.1, 1 and $10 \mu \mathrm{M})$, the cell viability was reduced to $27.12 \pm$ $6.71 \%$, as compared with the control group. Then, cell viability treated with glutamate plus different concentration of PF $(0.1,1$ and $10 \mu \mathrm{M})$ was increased to $40.52 \pm 4.74 \%, 50.67 \pm 5.06 \%$ and $82.03 \pm 8.78 \%$, respectively (Fig. 1), which indicated that PF can inhibit glutamate-induced reduction of cell viability.

\section{Effect of paeoniflorin on glutamate- induced apoptosis in PC12 cells}

To examine the effects of the apoptotic program, DNA fragmentation was analyzed. A typical DNA ladder appeared when cells were treated with glutamate at $30 \mathrm{mM}$ for $24 \mathrm{~h}$. However, the DNA ladder disappeared when cells were treated with a combination of glutamate at $30 \mathrm{mM}$ plus PF at different concentration (0.1, $1 \mu \mathrm{M})$ for $24 \mathrm{~h}$ (Fig. 2). To determine the apoptosis ratio caused by the drugs, apoptosis was analyzed by flow cytometry analysis. When glutamate was used alone, about $35.65 \%$ of cells were apoptotic at $24 \mathrm{~h}$. However, the combination of glutamate at $30 \mathrm{mM}$ and $\mathrm{PF}$ at different concentration $(0.1,1$ and $10 \mu \mathrm{M})$ reduced the apoptosis rate to $18.34 \% \pm 8.76,9.27 \pm 0.83 \%$ and $3.14 \pm 0.29 \%$, respectively $(P<0.01)$ (Fig. 3 ).

\section{Effect of paeoniflorin on glutamate- induced MMP in PC12 cells}

Lipophilic cationic dye Rh123 mainly gathered in the mitochondria and the intracellular intensity of Rh123 may reflect changes of mitochondrial membrane potential. After being treated with glutamate (30 mM) in DMEM medium for $24 \mathrm{~h}$, the MMP of PC12 cells was reduced to $27.35 \pm 2.74 \%$, as compared with the con- 
trol group. Then, MMP of cells treated with glutamate plus different concentration of PF (0.1, 1 and $10 \mu \mathrm{M})$ was increased to $42.35 \pm 6.81 \%, 69.31 \pm 5.94 \%$ and $78.26 \pm 8.57 \%$, respectively (Fig. 4), which indicated that PF can inhibit glutamate-induced reduction of MMP.

\section{Effect of paeoniflorin on $\mathrm{Bcl}-2 / \mathrm{Bax}$ signal pathway}

To determine whether apoptosis-related proteins including Bcl-2 and Bax participate in the process of apoptosis, cells were treated with or without different drugs and then the expression levels were examined by western blot. As shown in Figure 5, the expression level of $\mathrm{BCl}-2$ was significantly decreased when treated with $30 \mathrm{mM}$ glutamate alone and significantly increased in a concentration-dependent manner when treated with a combination of glutamate at $30 \mathrm{mM}$ plus $\mathrm{PF}$ at different concentration $(0.1,1,10 \mu \mathrm{M})$ for $24 \mathrm{~h}$ as compared with the control group. However, the expression level of Bax was indeed contrary to that of $\mathrm{Bcl}-2$. These results demonstrated that the protective effect of paeoniflorin on glutamate-induced apoptosis in $\mathrm{PC} 12$ cells was regulated through $\mathrm{Bcl}-2 / \mathrm{Bax}$ signal pathway.

\section{Discussion}

PF possesses wide pharmacological effects in nervous disorders such as Alzheimer's disease and Parkinson's disease [22]. In this study, we investigated the protective effect of PF on PC12 cells injury induced by glutamate. After treatment of PC12 cells with glutamate at $30 \mathrm{mM}$, a significant decrease in the cell viability and increase in the number of apoptotic cells appeared, confirming its neurotoxicity effect in $\mathrm{PC} 12$ cells. However, co-treatment with PF could increase the viability of cells exposed to glutamate alone, as well as a decrease in the percentage of apoptotic cells in a concentration-dependent manner. Apoptosis is now recognized as a normal feature in the development of the nervous system and may also play a role in neurodegenerative diseases, inappropriate cell death has been implicated in several neurodegenerative diseases [13]. Therefore, PF might be one of potential agents for treatment of these neurodegenerative diseases.

Mitochondria are the major source of energy in all eukaryotic cells, producing ATP through oxidative phosphorylation and the citric acid cycle. They regulate calcium homeostasis and modulate apoptosis through release of several cell death-inducing molecules [3,7].

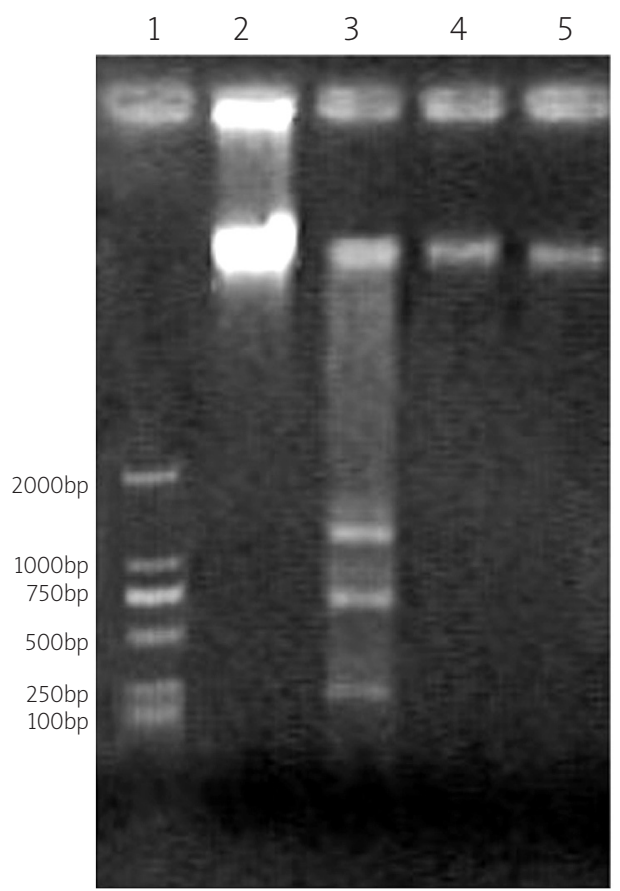

Fig. 2. The effect of PF on cell apoptosis by DNA fragmentation analysis. PC12 cells were exposed to drugs for $24 \mathrm{~h}$ and genomic DNA was extracted and separated by agarose gel electrophoresis. Lane 1: DNA marker; Lane 2: control; Lane 3: $24 \mathrm{~h}$ after glutamate treatment in the absence of PF; Lane 4-5: $24 \mathrm{~h}$ after glutamate treatment in the presence of $\mathrm{PF}(0.1,1 \mu \mathrm{M})$.

The pattern of mitochondrial inheritance has a profound impact on development and reproductive performance [17]. Previous studies and our experiment showed that glutamate treatment caused a significant decrease in the level of MMP. However, we found that co-treatment of PF could inhibit reduction of MMP on PC12 cells, suggesting that the neuroprotective effect of PF may be related to the mitochondrial death pathway.

Moreover, we investigated the expression profiles of two apoptosis-related proteins including Bcl-2 and Bax [14]. Apoptosis is associated with the activation of a genetic program in which apoptosis effector genes promote cell death. It is regulated by the action of the $\mathrm{Bcl}-2$ family of proteins, which includes anti- and proapoptotic members such as Bcl-2 and Bax [1,12,15,20,21]. It was reported that $\mathrm{Bcl}-2$ binds to the mitochondrial membrane, competitive binding with Bax and forming $\mathrm{BCl}-2 / \mathrm{Bax}$ heterodimer, which leads to closing mitochondrial permeability transition pore and preventing 

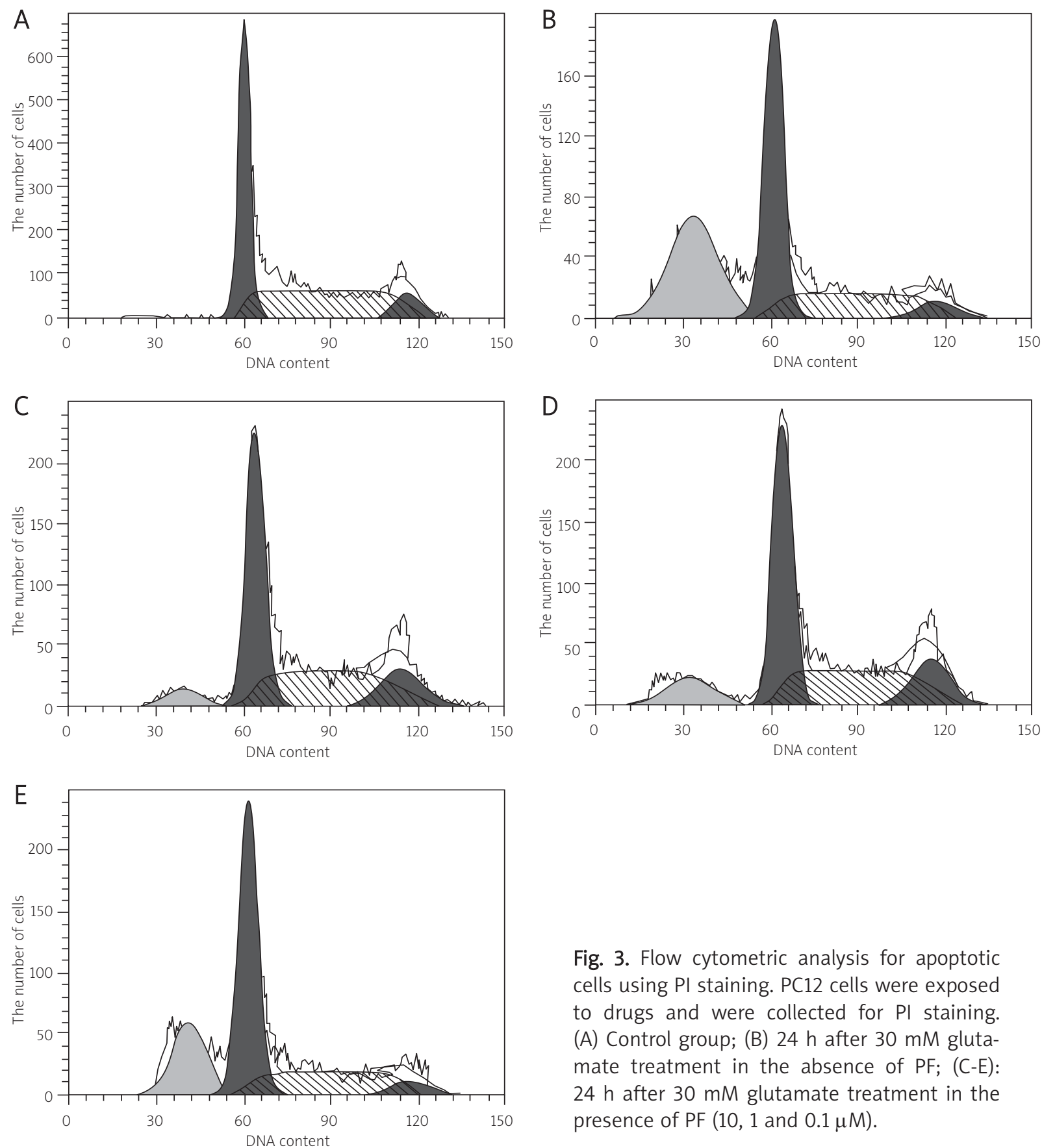

the release of cytochrome C, thereby inhibiting apoptosis. As a proapoptotic molecule, Bax can be combined into a Bax-Bax homodimer to form the composition of the mitochondrial membrane permeable channels, through which cytochrome $\mathrm{C}$ can transfer from mitochondrial into cytoplasm, which activate the caspaserelated apoptosis cascade, resulting in mitochondrial-

Fig. 3. Flow cytometric analysis for apoptotic cells using PI staining. PC12 cells were exposed to drugs and were collected for PI staining. (A) Control group; (B) $24 \mathrm{~h}$ after $30 \mathrm{mM}$ glutamate treatment in the absence of PF; (C-E): $24 \mathrm{~h}$ after $30 \mathrm{mM}$ glutamate treatment in the presence of PF $(10,1$ and $0.1 \mu \mathrm{M})$.

dependent apoptosis. In the present study, the expression level of Bcl-2 was significantly decreased when treated with glutamate alone and significantly dosedependent increased when treated with a combination of glutamate at $30 \mathrm{mM}$ plus PF at different concentration $(0.1,1,10 \mu \mathrm{M})$ for $24 \mathrm{~h}$ as compared with the control group. However, the expression level of Bax 


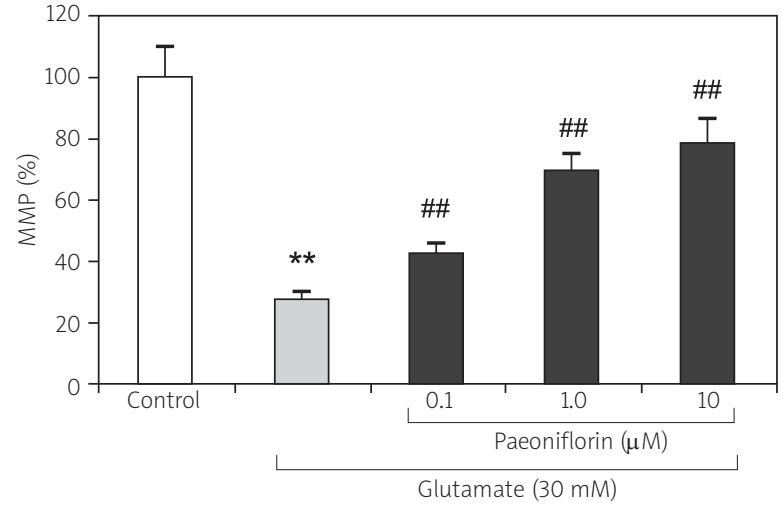

Fig. 4. The effect of PF on loss of MMP induced by glutamate in PC12 cells. (** $p<0.01$ vs. control group, ${ }^{\#} p<0.01$ vs. glutamate group).

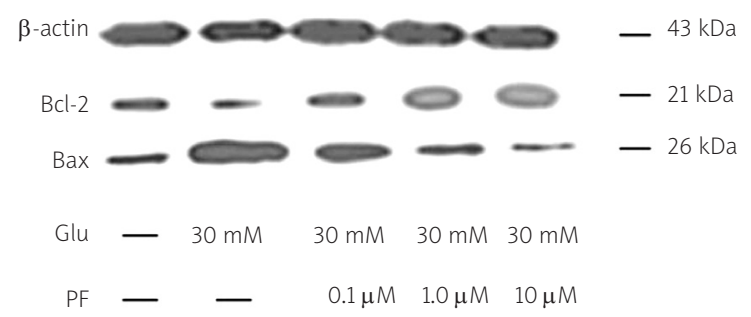

Fig. 5. The effect of PF on expression of $\mathrm{Bcl}-2$ and Bax protein in PC12 cells by western blot. $\beta$-actin was used as the internal control. Lane 1 : control; Lane 2: $24 \mathrm{~h}$ after $30 \mathrm{mM}$ glutamate treatment in the absence of PF; Lane 3-5: $24 \mathrm{~h}$ after $30 \mathrm{mM}$ glutamate treatment in the presence of PF (0.1, 1 and $10 \mu \mathrm{M})$.

was just the opposite. These results demonstrated that the protective effect of paeoniflorin on glutamateinduced apoptosis in PC12 cells was regulated through the $\mathrm{Bcl}-2 / \mathrm{Bax}$ signal pathway.

In summary, PF can remarkably inhibit glutamateinduced apoptosis in PC12 cells through regulating mitochondrial membrane potential and the Bcl-2/Bax signal pathway. These data suggest that PF has a protective effect on injured neurons and might be helpful in preventing neurotransmitter-related neurodegenerative disorders.

\section{Acknowledgements}

This work is supported by the Major Program of National Nature Significant Drug Discovery National Key Technologies Program of China during the $11^{\text {th }}$ Five-Year Plan Period (Grant No. 2009ZX09502-015); Postdoctoral Innovative Projects of Shandong (Grant No. 200801002); National TCM Project Application in the $11^{\text {th }}$ Five-Year Period (Grant No. 2008BAI51B02); National Major Fundamental Research Program of China (Grant No. 2009CB522802). The authors are very grateful to the Natural Science Foundation of Jiangsu Province (BK2011168).

\section{References}

1. Anvekar RA, Asciolla JJ, Missert DJ, Chipuk JE. Born to be alive: a role for the BCL-2 family in melanoma tumor cell survival, apoptosis, and treatment. Front Oncol 2011; 1: 1-4.

2. Hazell AS, Itzhak Y, Liu H, Norenberg MD. 1-Methyl-4-phenyl-1,2,3,6tetrahydropyridine (MPTP) decreases glutamate uptake in cultured astrocytes. J Neurochem 1997; 68: 2216-2219.

3. Jeong SY, Seol DW. The role of mitochondria in apoptosis. BMB Rep 2008; 41: 11-22.

4. Kanai Y, Bhide PG, Difiglia M, Hediger MA. Neuronal high-affinity glutamate transport in the rat central nervous system. Neuroreport 1995; 6: 2357-2362.

5. Kawakami Z, Kanno H, Ikarashi Y, Kase Y. Yokukansan, a kampo medicine, protects against glutamate cytotoxicity due to oxidative stress in PC12 cells. J Ethnopharmacol 2011; 134: 74-81.

6. Lee SM, Yoon MY, Park HR. Protective effects of Paeonia lactiflora pall on hydrogen peroxide-induced apoptosis in PC12 cells. Biosci Biotechnol Biochem 2008; 72: 1272-1277.

7. Lenaz G, Bovina C, D’Aurelio M, Fato R, Formiggini G, Genova ML, Giuliano G, Pich M, Paolucci U, Castelli G, Ventura B. Role of mitochondria in oxidative stress and aging. Ann N Y Acad Sci 2002; 959: 199-213.

8. Li N, Liu B, Dluzen DE, Jin Y. Protective effects of ginsenoside Rg2 against glutamate-induced neurotoxicity in PC12 cells. J Ethnopharmacol 2007; 111: 458-463.

9. Liu DZ, Zhu J, Jin DZ, Zhang LM, Ji X Q, Ye Y, Tang C P, Zhu XZ. Behavioral recovery following sub-chronic paeoniflorin administration in the striatal 6-OHDA lesion rodent model of Parkinson's disease. J Ethnopharmacol 2007; 112: 327-332.

10. Liu J, Jin DZ, Xiao L, Zhu XZ. Paeoniflorin attenuates chronic cerebral hypoperfusion-induced learning dysfunction and brain damage in rats. Brain Res 2006; 1089: 162-170.

11. Ma S, Liu H, Jiao H, Wang L, Chen L, Liang J, Zhao M, Zhang X. Neuroprotective effect of ginkgolide $\mathrm{K}$ on glutamate-induced cytotoxicity in PC 12 cells via inhibition of ROS generation and $\mathrm{Ca}(2+)$ influx. Neurotoxicology 2012; 33: 59-69.

12. MacGibbon GA, Lawlor PA, Sirimanne ES, Walton MR, Connor B, Young D, Williams C, Gluckman P, Faull RL, Hughes P, Dragunow M. Bax expression in mammalian neurons undergoing apoptosis, and in Alzheimer's disease hippocampus. Brain Res 1997; 750: 223-234. 
13. Mao QQ, Tsai SH, Ip SP, Che CT. Antidepressant-like effects of peony glycosides in mice. J Ethnopharmacol 2008; 119: 272-275.

14. Merry DE, Korsmeyer SJ. Bcl-2 gene family in the nervous system. Annu Rev Neurosci 1997; 20: 245-267.

15. Miller TM, Moulder KL, Knudson CM, Creedon DJ, Deshmukh M, Korsmeyer SJ, Johnson EMJr. Bax deletion further orders the cell death pathway in cerebellar granule cells and suggests a caspaseindependent pathway to cell death. J Cell Biol 1997; 139: 205-217.

16. Penugonda S, Mare S, Lutz P, Banks WA, Ercal N. Potentiation of lead-induced cell death in PC12 cells by glutamate: protection by $\mathrm{N}$-acetylcysteine amide (NACA), a novel thiol antioxidant. Toxicol Appl Pharmacol 2006; 216: 197-205.

17. Sano N, Obata M, Ooie Y, Komaru A. Mitochondrial DNA copy number is maintained during spermatogenesis and in the development of male larvae to sustain the doubly uniparental inheritance of mitochondrial DNA system in the blue mussel Mytilus galloprovincialis. Dev Growth Differ 2011; 53: 816-821.

18. Schwindt PC, Crill WE. Local and propagated dendritic action potentials evoked by glutamate iontophoresis on rat neocortical pyramidal neurons. J Neurophysiol 1997; 77: 2466-2483.

19. Yu HY, Liu MG, Liu DN, Shang GW, Wang Y, Qi C, Zhang KP, Song ZJ, Chen J. Antinociceptive effects of systemic paeoniflorin on bee venom-induced various 'phenotypes' of nociception and hypersensitivity. Pharmacol Biochem Behav 2007; 88: 131-140.

20. Yu J, Zhou X, He X, Dai M, Zhang Q. Curcumin Induces Apoptosis Involving bax/bcl-2 in Human Hepatoma SMMC-7721 Cells. Asian Pac J Cancer Prev 2011; 12: 1925-1929.

21. Zhao J, Wang LP, Nie JS, Niu Q. Effects of benzo(a)pryene on apoptosis of neuronal cells and expression of $\mathrm{Bcl}-2$ and Bax proteins in rat brain tissue. Zhonghua Lao Dong Wei Sheng Zhi Ye Bing Za Zhi 2011; 29: 820-824.

22. Zhong SZ, Ge QH, Li Q, Qu R, Ma SP. Paeoniflorin attentuates Abeta((1-42))-mediated neurotoxicity by regulating calcium homeostasis and ameliorating oxidative stress in hippocampus of rats. J Neurol Sci 2009; 280: 71-78. 